\title{
Children as voices and images for medicinal cannabis law reform
}

\author{
Ian Freckelton $\mathrm{AO} Q \mathrm{C}^{1,2,3}$
}

Accepted: 25 August 2021 / Published online: 31 October 2021

(c) Crown 2021

\begin{abstract}
This article situates the movement for the legalisation of medicinal cannabis within the bigger picture of the impetus toward recreational cannabis legalisation. It describes the role played by children with epileptic syndromes in the medicinal cannabis law reform campaigns in the United Kingdom, and Queensland, New South Wales and Victoria in Australia. Noting the 'rule of rescue' and the prominence in media campaigns of children in Australian and English cases of parental disputation with clinicians about treatment for their children, it reviews whether paediatric epilepsy is a suitable test case for the legalisation of medicinal cannabis. Taking into account the vested commercial interests of Big Cannabis, the current medicoscientific knowledge of the efficacy of medicinal cannabis in controlling paediatric epileptic seizures, and issues of dignity, health privacy, and the enduring digital footprints of media coverage, the article commences discussion about the ethics of the media, parents, politicians and entrepreneurial doctors utilising parents' testimonials about the effects of medicinal cannabis as part of the cannabis law reform movement.
\end{abstract}

Keywords Children as voices · Medicinal cannabis $\cdot$ Ethical issues $\cdot$ Law reform · Paediatric epilepsy $\cdot$ Cannabis legalisation $\cdot$ Medical marijuana

\section{Introduction}

Issues involving children are inherently emotive. Ill and dying children engender particularly poignant responses in all but the most hard-hearted among us (see Savulescu and Wilkinson 2018). Unsurprisingly, then, unwell children, when their

Ian Freckelton AO QC

I.Freckelton@ vicbar.com.au

1 Castan Chambers, Melbourne, Australia

2 University of Melbourne, Melbourne, Australia

3 C/o Foley's List, Owen Dixon Chambers, 205 William St, Melbourne, VIC 3000, Australia 
health status has a legal dimension and becomes publicly known, prompt high-profile coverage by the media in search of viewers and readers. A corollary is that such children have the potential to attract community attention and to be potent as vehicles for law reform campaigns and for those arguing for changes to clinical practice. They can also be attractive as photo-opportunities for politicians and organisations seeking to obtain kudos for law reform initiatives.

There have been many prominent examples of this phenomenon in recent years. Sometimes legislative reforms have even come to carry the eponymous title of a child. Victoria's anti-bullying legislation which came into force in July 2011 became known as "Brodie's Law" (Victorian State Government 2011). A bill introduced into the New South Wales Parliament to give legal personhood to foetuses of more than 20 weeks' gestation for the purposes of grievous bodily harm offences under criminal law was titled 'Zoe's Law' (Barratt 2014).

A series of recent high profile cases involving dying children at times dominated the attention of the media and through them the public, in part through publicity fanned by social media campaigns. A dying child in Western Australia, Oshin Kiszko, became highly publicised in the context of attempts made by his parents, contrary to medical advice, to take him into palliative care, abandoning the provision of chemotherapy and radiotherapy, after he was diagnosed and operated on for medulloblastoma, a form of brain tumour (Okninski 2016; Freckelton 2016a, 2016b). In the United Kingdom, Ashya King, diagnosed with medulloblastoma (O'Brien 2014), Charlie Gard, diagnosed with mitochondrial DNA depletion syndrome (Wheeler 2018; Ross 2020; Montgomery 2019; Laszewska-Hellriegel 2019; Freckelton 2016a, 2016b), Alfie Evans, diagnosed with GABA-transaminase deficiency (see Isaacs and Preisz 2019; Laszewska-Hellriegel 2019; Freckelton 2018), and Isaiah Haastrup diagnosed with severe hypoxic ischaemic encephalopathy (Jonas and Ryan 2020) attracted saturation publicity (Brick et al. 2020). This was in a context of their parents seeking diverse forms of local and international medical assistance for their children's serious health conditions, although in a number of the instances their parents' proposals for treatment were regarded by clinicians as futile and not in the best interests of the children (see Savulescu and Wilkinson 2018). In each case there was litigation that mostly supported the view of clinicians, in the latter three cases serial appellate litigation, but more particularly wholesale community engagement in relation to how children with seriously disabling conditions should be treated, as well as in relation to the role of parents in making decisions about their children's best interests in such sensitive circumstances. The parents argued that the law should support parents in making decisions about how, by whom and where their children should be treated. Some clinicians have argued that new approaches to decision-making are required in such situations (Birchley et al. 2017).

The Western Australian and United Kingdom cases were also distinguished by the parents' adoption of robust public positions in relation to what they believed was best for their children, including by using social media platforms and public relations consultants, as well as by ventilation of conflicts between parents of the ill children and treating clinicians (Moore and Lantos 2019; Freckelton 2018; Freckelton 2016a, b). The bringing of parent-doctor tensions into the public domain has prompted curial and clinician consternation, particularly in relation to the potential 
for generation of antagonism toward clinicians providing health services to children in fraught circumstances (see Auckland and Goold 2019; McDougall 2016; Freckelton 2018). The role of the media, politicians, and the media has come under scrutiny in these difficult circumstances.

In England and Australia children with epileptic conditions have often been the public face of campaigns to legalise medicinal cannabis, a particular form of treatment invested by some as having transformative potential for amelioration of symptoms associated with the condition. The fact that ill children in this context too have been brought into the glare of publicity and campaigning when they are in no position to assent or dissent to this taking place is troubling and confronting. It raises important ethical questions about the role of the media and the responsibilities of parents in publicising their ill children's health issues in order to secure particular forms of treatment that they consider to be in the best interests of their child or in support of a clinical or law reform agenda. It also creates a scenario in which dynamics between parents and clinicians can become strained and creates the potential for involvement by child protection and criminal investigation authorities, as well as, potentially, the courts.

This article contextualises the use of children in support of the social movement to decriminalise medicinal cannabis within the broader movement to decriminalise cannabis generally. Clearly if cannabis is legalised for medicinal purposes, this will give a fillip to the quest to decriminalise it also for recreational purposes by reducing its stigma and reframing it in a benign light. The issue canvassed by this article is the legitimacy of utilising children as a vehicle for reform to the law or clinical practice, taking into account the powerful commercial interests in the Big Cannabis lobby that have the potential to introduce a complicating dynamic into the community discourse and public perceptions of the relevance of therapeutic options for serious health conditions experienced by children.

\section{The cannabis law reform agenda}

Cannabis cultivation, manufacture and distribution is a substantial and profitable industry - both where it is legal (Summers 2018) and where it is illegal (Wilkins et al. 2005). It has been contended that the legal cannabis industry may exceed \$US66 billion in revenue by the end of 2025, while in the United States the illegal industry, valued in 2019 at \$US12 billion, is expected to be growing at a compound annual rate of between $24.1 \%$ and $33 \%$ by 2024/2025 (Gale 2020; Kolmar 2021). It has been estimated that Americans spend roughly \$US40 billion a year on a combination of legal and illegal cannabis. (Halperin 2018).

The movement to legalise recreational cannabis is gathering momentum and countries where cannabis possession has been decriminalised now include Canada, Georgia, South Africa, Uruguay and 17 states and two territories in the United States. In other countries, such as the Netherlands, tolerance is extended to personal use. In Australia the ACT formally legalised the personal use of cannabis in January 
2020 by the Drugs of Dependence (Personal Cannabis Use) Amendment Act 2019 (ACT).

The changes to the legality of personal cannabis use and possession are creating a lawful industry where previously the industry was unlawful. In turn this is generating commercial opportunities with substantial corporations and interests vying for ascendancy in the nascent and highly profitable industry (Hageseth, D'Agnese, 2015). Commentators have warned, though, of the dangers of "Big Cannabis"/"Big Weed", a corporatised industry model spawned from the alcohol, tobacco and pharmaceutical sectors. Roberts (2021), has identified the competitive issues in the industry and observed that:

Regulatory complexities include restrictive and often confusing limits on who can grow and sell cannabis. Many states that now have booming cannabis industries are home to companies that have grown into multi-state operators also restrict the number of sales or cultivation licenses they issue. This has helped guarantee that competition for these limited state-granted permits is fierce and expensive. Fees for these licenses run in the tens of thousands of dollars or more; other compliance costs raise the barrier for entry into the weed market even further. Any existing small businesses are faced with a choice: try and compete in an uneven landscape or cash out while they can and be swallowed up.

In Australia a merger of the locally owned Australian Natural Therapeutics Group (ANTG) and Canadian-owned Asterion Cannabis Inc is reported to have hastened construction of a $\$ A 400$ million facility for cultivation, manufacture and research of medicinal products near Toowoomba in Queensland (Daly 2021; Asterion 2021). It is not coincidental that many of the larger purveyors of medicinal cannabis are also producers and distributors of recreational cannabis (see Kolmar 2021; Reiff 2021). Aside from other considerations, this enables utilisation of cultivation and manufacturing expertise in cannabis. What it does highlight though is that the cannabis industry stands to gain substantially from the first step in cannabis legalisation - cannabis asserted to be for medicinal purposes.

However, reform efforts have not been uniformly successful, especially in respect of recreational cannabis. For instance, in October 2020 50.7\% of New Zealand's voters by a majority of 67,662 votes decided against the legalisation and regulation of recreational cannabis at a public referendum held as part of the general election (Rychert and Wilkins 2021). In terms of the lessons to be learned, Fischer and Hall (2021) have observed that:

While advocates of legalization frame it as a public health and safety-oriented policy, for many opponents legalization remains an issue morality. Policy discourses and debates popularly revolve around pleasure, health harms, risks to young people, and especially mental health (e.g., psychosis). These perspectives and issues are conceptually similar, and useful for comparison, to those raised in response to proposals to legalize and regulate commercial sex work that have been tabled - while commonly unsuccessful - in some places. Public attitudes on these issues of morality continue to divide opinion in liberal 
Western societies. These, by contrast, crucially differ from initiatives to legalize 'medically-assisted dying' or to allow 'medical cannabis use' which are predominantly viewed as compassionate or care-oriented responses to (suffering) others, and therefore attract much greater acceptance and support across different socio-ideological perspectives

\section{Medicinal cannabis law reform}

The lobby to decriminalise cannabis for medicinal purpose because of its asserted capacity to heal and relieve pain has a lengthy history (see Joy and Mack 2000; Booth 2003; Backes 2014; Wedman-St Louis 2019; Younger 2018; Bridgeman 2017; Freckelton 2016a, 2016b; Russo 2003). Latterly, in Australia the Victorian Law Reform Commission (2015) recommended a scheme for the legalisation of a closely regulated scheme for cultivation and manufacture of cannabis products for medicinal use. Its report was implemented by the Access to Medicinal Cannabis Act 2016 (Vic), followed shortly afterwards by the Public Health (Medicinal Cannabis) Act 2016 (Qld), prompting the Commonwealth to intervene legislatively to establish a national scheme through the Therapeutic Goods Administration. By the Narcotic Drugs Amendment Act 2016 (Cth) a national licensing and permit scheme for the cultivation, production and manufacture of cannabis for medicinal and research purposes was established. In principle, the scheme has significant commercial ramifications. On 4 January 2018, for instance, Mr Hunt, the Federal Minister for Health announced the government's aspiration for Australia to become an exporter of medicinal cannabis and from February 2018 it became lawful to export medicinal cannabis products (Hunt 2018).

Under current Australian law medical practitioners are permitted to apply under the Therapeutic Goods Administration's Special Access Scheme Category (Therapeutic Goods Administration 2021a) or via an Authorised Prescriber (Therapeutic Goods Administration, 2021b) to prescribe medicinal cannabis products for a particular patient (see Gleeson 2020). Under subregulation 5(2) of the Customs (Prohibited Import) Regulations 1956 (Cth), too, a traveller (or traveller's carer) on board a ship or aircraft entering Australia can carry up to three months' supply of a therapeutic good for the medical treatment of that passenger or another passenger under his or her care, where the good was prescribed by a medical practitioner. Evidence that the amount imported does not exceed the amount specified in the prescription for a three month period may be required to be provided on entry into Australia (Therapeutic Goods Administration (2019).

Most approvals under the Special Access Scheme are for the treatment of chronic non-cancer pain. This includes conditions such as arthritis, lower back pain, neck pain and various forms of neuropathic pain. These are typically treated with oral solutions that contain the psychoactive THC and sometimes additional cannabidiol (CBD). Other common conditions among those approved include anxiety, cancerrelated symptoms (e.g., pain, nausea, anorexia), epilepsy, insomnia, and spasticity in multiple sclerosis; CBD-only products are being used in all of these conditions, but there is a greater use of them in patients with epilepsy and anxiety. (Arnold et al. 
2020) The Therapeutic Goods Administration has published a range of guidance documents in relation to medicinal cannabis (Therapeutic Goods Administration 2020).

As Gleeson (2020) has usefully pointed out, there are a number of different voices that are heard in debates about the legalisation of medicinal cannabis - the 'dominant voice' (including the medical establishment) that asserts the status quo; a 'more moderate middle ground voice' that seeks to embrace cannabis as a therapeutic substance and a means of delivering compassion to patients; and a 'radical, reformist voice' conceiving of cannabis as a mainstream substance for consumption that should be normalised and legalised. This article contends that another voice has been utilised by reformists - that of children - and it reflects on the ethics of the invocation of this voice.

Medicinal cannabis is promoted by enthusiasts (the radical voice) as a cure and an effective treatment for a great many conditions without the existence of any significant risk of side-effects. For instance, the Medicinal Cannabis Users Association of Australia blurs the distinction between the medicinal and recreational properties of cannabis and argues that:

The entourage effect of whole plant extracts is VITAL to the healing properties of Cannabis when used medicinally and it should be our right to access and use whole plant natural cannabis for preventative and curative measures if we so choose.

International evidence shows that cannabis has contributed to lowering dependence on opioids and thus helping to relieve the opioid crisis.

Cannabis has been used as a Recreational therapy by over 3 million Australians on a regular basis for decades for the relief of Stress. Recreation is an established and legitimate therapy for the relief of stress which can lead to all kinds of physical health problems. All users, no matter what the intent, are targeted by police and in order for this to stop we support legalisation is the answer (Medical Cannabis Users Association of Australia 2021).

The Medicinal Cannabis Clinic promotes itself, stating that:

Our doctors will apply to the Department of Health to gain approval to prescribe you Medicinal Marijuana products.

The Department of Health Consider "any chronic condition lasting three months or more that has not responded to conventional medical treatments." Chronic conditions can include Chronic pain, cancer pain, anxiety, PTSD. Please see a more comprehensive list below.

Our doctors have received TGA approvals for over 55 conditions. ... We consult on:

- Chronic Pain,

- Cancer Pain,

- Anxiety,

- Insomnia, 
- Fibromyalgia,

- Palliative Care,

- Epilepsy,

- Parkinson's Disease,

- Migraine,

- Multiple Sclerosis,

- Nerve Pain,

- Autism,

- Schizophrenia

- Depression

- PTSD

- Blood Glucose Control

- Insomnia

- Alzheimer

- Dystonia

- IBS and more. (Cannabis Doctors Australia, ACT 2021)

It is but one of multiple clinics that have come into being since 2017 that provide cannabis medicine-specific services. In 2018 it was asserted, for instance, that ten new medicinal cannabis clinics were scheduled to open in Melbourne alone during the next year (Connor 2018). It is apparent that the cannabis clinic phenomenon is highly commercially competitive (Canna Reviews Australia 2021). The specialised nature of such clinics has clear advantages in terms of the information able to be provided to patients, but a challenge exists for the clinics in terms of integration and relationships with general medicine in their provision of services.

However, in spite of the popularisation of medicinal cannabis therapies, the evidence for the therapeutic efficacy of medicinal cannabis is not uniformly endorsed and, in fact, there remains a significant level of scepticism in this regard amongst many medical practitioners. As of 1 August 2021, the Therapeutic Goods Administration publishes on its website a reserved analysis (dating back to 21 December 2017):

There is some low to moderate evidence to suggest that medicinal cannabis products may be effective for treating the pain symptoms of MS, although this is inconsistent. Studies differ as to whether medicinal cannabis products can help improve bladder function, sleep, quality of life, ataxia/tremor and disability/disease progression. ...

There is some evidence that cannabinoids can reduce pain in both MS related neuropathic pain and non-MS related neuropathic pain, but for many people the reduction in pain may be modest. There is, however, insufficient information to make a conclusion about cannabinoids for the treatment of pain associated with arthritis and fibromyalgia. Current studies show no evidence that medicinal cannabis can improve overall quality of life or physical functioning. There is also some evidence that it can improve sleep. ... There are some reports that medicinal cannabis products (in particular THC and related 
substances) relieved the symptoms of CINV. However, the number of studies is small and the quality of published evidence is low to moderate. While several studies found that the medicinal cannabis products were as effective as the prescription medicine it was compared with, most of the research studies were carried out some years ago, and in recent years much more effective prescription medicines for nausea and vomiting have become available. ... It is important to note that some side-effects from medicinal cannabis treatment may be similar to symptoms of distress often experienced by people in endof-life care. As there are very few studies on medicinal cannabis treatment in palliative care, it should be used only after standard treatments have failed. It is possible that medicinal cannabis will interact with chemotherapy and other medications used in palliative care. More studies are needed to better understand this. (Therapeutic Goods Administration 2017)

The Australian Medical Association too retains a qualified position in respect of medicinal cannabis and, while it accepts that "there is a growing body of evidence regarding the therapeutic use of cannabinoids", continues to express the view that "it is still experimental". (Australian Medical Association 2020).

In 2021 the Faculty of Pain Medicine of the Australian and New Zealand College of Anaesthetists, reiterated its opposition to the undiscerning use of medicinal cannabis for the alleviation of pain and its concerns about the state of research in relation to efficacy:

The Faculty of Pain Medicine of the Australian and New Zealand College of Anaesthetists says there needs to be more clinical evidence about the efficacy of medicinal cannabis before use as a treatment for chronic, non-cancer pain.

The sixth recommendation released today for Australian doctors says: Do not prescribe currently available cannabinoid products to treat chronic non-cancer pain unless part of a registered clinical trial. The recommendation coincides with a recent statement by the leading global authority on pain research, the International Association for the Study of Pain (IASP), which says there is a lack of sufficient evidence to endorse the use of medicinal cannabis to treat pain. (Faculty of Pain Medicine of the Australian and New Zealand College of Anaesthetists 2021; International Association for the Study of Pain 2021; Vagg 2021).

Thus, the issue of clinical efficacy and advisability of the use of medicinal cannabis for a number of conditions remains unresolved. I turn now to the issues as they pertain to children with epileptic conditions.

\section{Children as the face of medicinal cannabis law reform}

The agenda to legalise medicinal cannabis has featured children in a number of jurisdictions. In England two young persons with epileptic conditions were at the forefront of changes. 
In 201711 year old Billy Caldwell became the first child to be prescribed medicinal cannabis oil on the National Health Service. However, the Home Office later ordered Billy's general practitioner not to renew the prescription as it contravened United Kingdom law. This prompted Billy's mother to take him to Canada to procure the medication where by that time it had become legal. (Busby 2018c) On the return of Billy and his mother to England, his cannabis oil was seized by customs agents at Heathrow Airport in June 2018. His mother maintained to the media that without the oil Billy suffered up to 100 epileptic seizures a day (Busby 2018a). She asserted that, after the cannabis oil was not returned to him, Billy suffered his first seizure in 300 days and recommenced to suffer dozens of seizures a day (Busby 2018b). This resulted in widespread criticism within the community. An all-party parliamentary group of medical practitioners, including a former Health Minister and Justice Minister, pledged to make policy recommendations to remedy the situation.

A Home Office spokesperson responded to the clamour for assistance for Billy, stating: "The Home Office is sympathetic to the difficult and rare situation that Billy and his family are faced with. Whilst we recognise that people with debilitating illnesses are looking to alleviate their symptoms, Border Force has a duty to stop banned substances from entering the UK." (Busby 2018b).

Within a month, though, under mounting public pressure, the Home Secretary, Sajid Javid, intervened and granted an emergency licence for cannabis oil to be administered to Billy at home. Northern Ireland's authorities followed suit (Busby 2018c) and the Home Secretary announced that the Advisory Council on the Misuse of Drugs would assess whether cannabis should be reclassified to make it easier to enable research to be conducted on the efficacy of medicinal cannabis. He stated that if the review identified significant medical and therapeutic benefits then cannabis could be rescheduled to permit medicinal use. (Grierson and Busby 2018) Tellingly, Billy's mother made it clear that she saw her son's case through the prism of a wider effort for children to gain access to medicines than the United Kingdom's scheduling process permitted. (Busby 2018c). This resulted in a change to the law on 1 November 2018 with a rescheduling of medicinal cannabis.

The other child who played a vital role in medicinal cannabis law reform in the United Kingdom was Alfie Dingley who also suffered from a rare form of epilepsy, caused by a mutation in the gene that codes for the protein protocadherin 19 . He was said to suffer up to 500 seizures a month before he was prescribed medicinal cannabis (Busby 2018d). In 2017 his mother commenced a campaign for Alfie to be prescribed cannabis medications and emigrated to The Netherlands after raising the money for the move. There he was given CBD oil, Bedrolite manufactured by the Dutch company Bedrocan, along with THC oil (Bedrocan's Bedica). She maintained that Alfie's seizures stopped for 40 days and his cognitive development improved (Deacon 2019; Busby 2018d).

Alfie's mother was given work as a paid patient advocate specialist for European Cannabis Holdings, a medical cannabis investment group (Deacon 2019) and became a "Patient Advocacy Specialist" with the Lyphe Group, a portfolio of companies responsible for the launch of the United Kingdom's first medical cannabis clinic (Nadler 2019). Ultimately Alfie became the first person in the United Kingdom to receive a permanent medicinal cannabis licence. 
However, in 2021, Alfie's mother was given two weeks' notice by the Department of Health and Social Care that due to the end of the Brexit transitions period "prescriptions issued in the UK can no longer be dispensed in an EU member state" (O'Carroll 2021). Alfie's mother returned to campaigning, utilising a Facebook page, "Alfie's Hope" (https://www.facebook.com/alfieshope) and secured an extension until January 2022. She stated that she knew of only three children in the United Kingdom who could obtain their medicinal cannabis on NHS prescriptions, but at least 100 other families were needing the specialist drug and spending large sums of money to obtain it (Nelson 2021), with at least 1.4 million people sourcing cannabis illegally (Frew 2021). A Department of Health and Social Care spokesperson has been quoted as having said: 'We recognise the huge challenges faced by children living with rare and hard to treat conditions. The government changed the law to allow specialist doctors to prescribe unlicensed cannabis-based products for medicinal use where it is clinically appropriate and in the best interests of patients.' (Frew 2021). By June 2021 Alfie's mother was reported to be seeking a meeting with the Prime Minister asking for a meeting 'The firm she co-founded, Maple Tree Consultants, says Britain exports 97 tons of medicinal cannabis a year $-45 \%$ of the world market.' (Nelson, 2021)

In Queensland Suli Peek became a public face of the campaign to legalise medicinal cannabis. In 2015 when she was aged seven and suffering between 100 and 200 epileptic seizures a day that were not relieved by medication, her parents sourced illicit medicinal cannabis for her in an attempt to alleviate her symptoms. (See Gregoire 2020) When her treaters were notified, the hospital was not prepared to enable Suli to receive cannabis oil (Mellor 2018) while on its premises and allegedly notified the Child Protection Unit. However, her parents claimed that her seizures improved markedly with medicinal cannabis and that for a time she commenced to meet her schooling milestones. A public campaign was mounted by her parents for the legalisation of medicinal cannabis and the giving of amnesty to parents who broke cannabis possession laws (see Keyte 2017), her father, Steve Peek, having become a director of 'United in Compassion' in Queensland (Peek). Allegedly, Queensland Premier Anastacia Palasczuk offered to assist her to obtain cannabis oil and meetings took place with senior health officials in the Queensland bureaucracy (Gregoire 2020), as well as with Epilepsy Action Australia (Mellor 2018).

Ultimately, Suli passed away in 2017 and a further campaign was mounted by her parents and supporters to secure a coronial inquest into her death (Mellor 2018) in the midst of a criminal investigation into the medicinal cannabis that her parents had sourced for her (Gregoire 2020). The Vice-President of the Queensland branch of the Australian Medical Association declined to comment on the campaign but emphasised the difficult position in which medical practitioners could find themselves when conflicts evolved between practitioners and family members: 'specialists are under a huge amount of pressure for the wellbeing of those patients and they can be under a huge amount of emotional pressure from the patient's family. It's a very hard job that they do' (Mellor 2018).

In New South Wales, a public face of the campaign to change the medicinal cannabis laws was Luella Oudshoorn, a young child with a rare form of epilepsy, West syndrome, which results in the suffering of hundreds of seizures a day. Her 
parents went public with the claim that cannabis oil, in this instance CBDa (cannabidiolic acid), which they sourced for her, 'was nothing short of miraculous' (Andaloro 2020; Wilkie 2020) and avoided Baby Luella having to be placed in an induced coma (Butcher 2020). Her parents embarked on a media campaign to lobby against the difficulty in obtaining medicinal cannabis that was not prohibitively expensive. The campaign was embraced by Cannabis Club Australia, whose motto is 'Cannabis is the plant, that can' (Cannabis Club Australia 2020). Luella's parents maintained to a journalist that they had experienced difficulty getting access to cannabis oil during the COVID-19 pandemic but as of late 2020 had found a supplier with whom they hoped to continue working (Butcher 2020).

The first public face of the medicinal cannabis campaign in Victoria was Tara O'Connell, a child with Dravet syndrome (see below). Tara was said to have experienced between 65 and 200 seizures per day until commencing to use illegal cannabis treatment (Tozer 2015). Prior to the 2014 Victorian election, the then opposition leader, Daniel Andrews, announced alongside the O'Connell family that if the Labor Party won the impending election, it would legalise medicinal cannabis (Cook 2014).

Cooper Wallace was the second public face of the campaign in Victoria. He was described as a "poster-child for the benefits of medicinal cannabis"(Rose 2015). His medical difficulties commenced after contracting bacterial meningitis which left him with severe brain damage, cerebral abscesses, hydrocephalus, epilepsy and cerebral palsy. At the age of four he spent more than half of 2013 in hospital due to severe epileptic seizures until his parents sought out illegal cannabis oil. Cooper's parents identified significant improvements as soon as Cooper received the cannabis oil they procured for him on the black market but after participating in a current affairs program in which his mother related the benefits experienced by Cooper, the family home was raided and various substances were seized (Johns and Spooner 2014). Ultimately, on advice from the Director of Public Prosecutions, criminal charges did not proceed.

Standing outside Cooper Wallace's house, after taking office, the new Premier of Victoria, Daniel Andrews, announced the government's intention to legalise medicinal cannabis and to give a reference to the Victorian Law Reform Commission to be advised how best this could be implemented (Desloires and Battersbly 2014). When the Commission's 42 recommendations were accepted by the government, and the Access to Medicinal Cannabis Act 2016 (Vic) was foreshadowed by the Premier, he said that Cooper Wallace had had a profound effect on his views: "I've had one of those most powerful, one of the most emotional stories told to me in all my days, about a loving family who'd been sent home to plan for a little boy's funeral and instead, through medicinal cannabis had been able to see their son transformed, to see the family transformed. That's pretty powerful stuff. This was the right decision to make" (Thomsen 2015). 


\section{Children and cannabis}

In light of the prominence of paediatric epilepsy as a lever for medicinal cannabis law reform, it is useful to look to its invocation and the evolving evidence underlying claims for its utility in addressing seizure symptomatology. There of the significant diseases for which it is promoted as a treatment by the medicinal cannabis lobby are Dravet's syndrome, Lennox-Gastaut syndrome and West syndrome.

Dravet's syndrome (also known as Severe Monoclonic Epilepsy of Infancy (SMEI)) is a rare sub-category of intractable epilepsy (Villas et al. 2017). It is a form of epileptic encephalopathy (Catarino et al. 2011) with an estimated incidence of 1: 15,700 persons, $75-80 \%$ of whom have a mutation in their SCN1A gene. It has a common comorbidity of developmental delay, as well as abnormal EEGs, and is characterised by frequent and prolonged seizures (see Dravet Foundation). Many patients experience gait disturbances, as well as epileptic seizures (Villas et al. 2017).

Lennox-Gastaut syndrome is a rare and severe form of epileptic encephalopathy with onset in children usually between the ages of three and five (Resnick and Sheth 2017). It is diagnosed in approximately $2-5 \%$ of children with epilepsy and 1-2\% of all patients with epilepsy. It is significantly drug-resistant and complete seizure control is often not achievable with conventional medications. Many children with the syndrome are also developmentally delayed. It is characterised by a combination of seizure types. It can be cryptogenic in children with a previously normal development or symptomatic or congenital or acquired brain anomalies. It is characterised by high rates of seizures and its long term outcome is poor (Asadi-Pooya 2017).

West syndrome, first described by Dr William West in the 1840s, is a catastrophic form of severe epileptic encephalopathy occurring in the first year of life. It is characterised by a triad of infantile spasms, psychomotor deterioration and a hypsarrhythymic EEG pattern. (Lagae et al. 2010) It is commonly associated with poor long-term outcome and development of other seizure types, including LennoxGastaut syndrome, impaired cognitive and psychosocial functioning. Its aetiology can be both cryptogenic and idiopathic (Cvitanovic-Sojat et al. 2005; Specchio et al. 2010)).

Thus Dravet's syndrome, Lennox-Gastaut syndrome and West syndrome are atypical forms of childhood epilepsy. They are encephalopathic, their aetiologies are uncertain and they have poor prognoses. They have comorbidities and are problematic to treat. They are intensely distressing for carers because they are characterised by high numbers of seizures and can be treatment-resistant. The nature of the syndromes, as well as others (e.g., Doose syndrome and Otahara syndrome) has encouraged parents in a number of countries to seek alternative solutions such as medicinal cannabis (see Aguire-Velazquez 2017).

While at the time of the report of the Victorian Law Reform Commission in 2015 the state of research in relation to the efficacy of medicinal cannabis for relieving the symptoms of paediatric epilepsy was "characterised by uncertainty and change" (Victorian Law Reform Commission 2015, p. 2.87), it was noted that there was "emerging research support for the effectiveness of cannabis in relieving 
the symptoms of epilepsy, especially for those with juvenile syndromes" (Victorian Law Reform Commission 2015, p. 2.94). There is now more reason for optimism in respect of the use of cannabidiol (CBD), alone or in conjunction with THC, for the treatment of epileptic conditions for some paediatric patients.

Cannabidiol is one of approximately 100 components of the cannabis plant. It is non-psychoactive - it does not contain the euphoriant effects of tetrahydrocannabinol (THC) (Chen et al. 2019), whose effects are sought after by recreational users of cannabis,

As of 21 December 2017 the Therapeutic Goods Administration observed that:

There is some evidence to support using medicinal cannabis in the treatment of certain childhood epilepsies.

Cannabidiol (CBD) is the substance featured in most published evidence on medicinal cannabis as an epilepsy treatment. However, this evidence is when it is used as an add-on to current treatments in drug-resistant epilepsy in children and young adults up to 25 years where use of several anti-epileptic drugs has not controlled their condition. In patients with paediatric-onset drug-resistant epilepsy, CBD products reduced seizure frequency by 50 per cent or more in up to half of the patients and achieved seizure freedom in a small number of patients. Several studies have reported improved quality of life in paediatric and adult groups, but overall there are few studies of how effective CBD is in treating adult epilepsy. There is not enough evidence to recommend this treatment for adults (Therapeutic Goods Administration 2017).

However, ongoing research has taken the issue further from a medico-scientific perspective although "the results from the pivotal studies with plant-derived, pharmaceutical grade CBD cannot simply be transferred to other epilepsy types or CBD of any origins. Because of the high demands and expectations that patients with epilepsy and their caregivers have regarding CBD information outlining the proven facts and potential risks is essential" (von Wrede et al. 2021).

In an influential 2017 randomised, double-blind, placebo-controlled trial of CBD in Dravet syndrome (Devinsky et al. 2017), 120 children and adolescents were given $20 \mathrm{mg} / \mathrm{kg} /$ day of CBD over a 14-week period. The median reduction in convulsive seizures was $38.9 \%$ vs $13.3 \%$ for those in the placebo cohort. In a 2020 doubleblind, placebo-controlled, randomised trial involving 199 adolescents with Dravet syndrome, median convulsive seizure reduction was $48.7 \%$ in the $10 \mathrm{mg} / \mathrm{kg} / \mathrm{day}$ group and $45.7 \%$ in the $20 \mathrm{mg} / \mathrm{kg}$ /day group, as against 26.9 in the placebo group (Miller et al. 2020).

In respect of Lennox-Gastaut syndrome two phase III studies have been carried out with a focus on drop seizures (atonic seizures, also called akinetic seizures, with the potential to cause the person to drop to the ground). In the first, which involved 225 patients over 14 weeks, the reduction in drop seizures for $10 \mathrm{mg} / \mathrm{kg} /$ day was $37.2 \%$ and for $20 \mathrm{mg} / \mathrm{kg} /$ day was $41.9 \%$ as against $17.2 \%$ for those in the placebo group (Devinsky et al. 2018). In another study involving 171 patients a reduction in drop seizures of $43 \%$ as against $21.8 \%$ in the placebo group was found. (Thiele et al. 2018). 
On 18 December 2019 the National Institute for Health and Care Excellence in the United Kingdom (NICE 2019) recommended cannabidiol in conjunction with clobazam, a benzodiazepine used to reduce seizure activity, as an option for treating paediatric seizures if drop seizures are not well enough controlled after trials of two or more anti-epileptic drugs. It stated that:

The cost-effectiveness estimates are uncertain for cannabidiol because of some of the assumptions in the company's model. The cost-effectiveness estimates do not include the benefits of:

- Reducing the number of non-drop seizures.

- Improving the quality of life of the siblings of people with Lennox-Gastaut syndrome.

When taking both the uncertainties and the uncaptured benefits into account, cannabidiol is considered an appropriate use of NHS resources, and is recommended as an option for treating Lennox-Gastaut syndrome on the NHS.

To similar effect a 2021 review of the available literature (Von Wred et al. 2021) concluded that: 'Cannabidiol is an interesting, but very expensive treatment option for drug-resistant epilepsy. Several studies showed promising results for treating special epileptic encephalopathies, but the efficacy for treating epilepsy in general is still under investigation. Though high rates of side effects have been reported, withdrawal is rare and there is growing evidence of a positive influence of CBD on behavior and cognition. Difficulties involving CBD treatment are costs, drug-drug interactions, as well as the complex and emotionally triggered preconception reflecting the ideas patients and caregivers have regarding $\mathrm{CBD}$ as a cannabis-derived option.'

In short, therefore, the evidence is accumulating that CBD, at least as an adjuvant, for Dravet syndrome, Lennox-Gastaut syndrome and West syndrome can be useful in seizure reduction for some children. It is clear that it is not a panacea or to be regarded as a cure. It has a significant incidence of mild to moderate side-effects, and the longer term effects of CBD usage are not yet known.

The combination of evidence led the Federal Drugs Administration (FDA) in the United States in 2018 to approve Epidyolex, a purified CBD extract, to treat seizure disorders in patients aged two years or older. On 1 May 2021 oral liquid CBD (Epidyolex) also became available in Australia under the Pharmaceutical Benefits Scheme for Dravet's syndrome if a child's seizures are assessed by a neurologist as inadequately controlled despite treatment with at least two antiepileptic medicines. The change was estimated by the Minister for Health as having the potential to benefit 116 children (Hunt 2021). 


\section{Research developments in respect of the efficacy of medicinal cannabis for other conditions}

However, while the evidence in respect of these unusual paediatric syndromes is looking promising, the picture in terms of the efficacy of medicinal cannabis more broadly is much more complex and the efficacy outcomes are varied. For instance, a 2019 scoping review of 72 systematic reviews (Pratt et al. 2019) found that half of the reviews were only of "modest quality" and displayed a disparity of reported results; many were unable to provide a definitive statement regarding the therapeutic effectiveness of cannabis. A similar result was arrived at in a review of systematic reviews in relation to cannabis-based medicines for chronic pain management (Hauser et al. 2018; Nugent e al. 2017). It concluded that there were consistent results that there was insufficient evidence of any cannabis-based medicine for pain management in patients with rheumatic diseases and in cancer pain, while there were inconsistent results in systematic reviews on the efficacy of cannabis-based medicines in neuropathic pain. There were inconsistent results too in respect of tolerability and safety for any chronic pain.

While there is a significant literature on the long-term effects of recreational cannabis use, including mood disorders, exacerbation of psychotic disorders in those who are vulnerable by reason of neurocognitive impairment and cannabis use disorders, as well as cardiovascular and respiratory disorders (see Karila et al. 2014), side-effects from medicinal cannabis tend to be reasonably minor (see e.g., Reis et al. 2019), especially by contrast with those from opioids. They are also related to some degree with the form of administration and the amount of THC in the medication. Minor effects such as drowsiness and dizziness are commonly reported (see e.g., (Pratt et al. 2019) but deaths due to cannabis toxicity generally and, in particular due to medicinal cannabis, are almost unknown (Zahra et al. 2020).

\section{The ethical issues}

There is a global industry that is already making substantial profits from both the legal and illegal activities of cannabis cultivation, manufacture and distribution. The industry aspires to grow even further on the back of attaining the respectability of lawful status. A vital strategic step in that regard is compassionate legalisation of medicinal cannabis, after which the second stage of the campaign for decriminalisation of cannabis can be pursued with greater confidence and in a more receptive community environment.

There is an undeniable link between the movements for recreational cannabis law reform and medicinal cannabis law reform. As Lancaster, Seear and Ritter have convincingly argued, the two cannot properly be separated, notwithstanding protestations to the contrary, and the one has the potential to leverage off the other politically (Lancaster et al. 2017). To the extent that reform of the law criminalising use and possession of cannabis for medicinal purposes takes place, stigma is reduced and a green and benign characterisation of cannabis (Clarke and Merlin 2016) is likely 
to infuse community consciousness and render legalisation of recreational cannabis more politically acceptable. Underpinning the legalisation of medicinal cannabis is the argument that it is said to be unknown for it to cause deaths or serious harm (see though National Academies 2017). While the use of smoked euphoriant cannabis is fundamentally different from the use of cannabis for therapeutic purposes, especially under medical supervision, an elision of medicinal and recreational cannabis can be politically beguiling. It can be assumed with confidence that this fact is not lost on those pursuing a cannabis legalisation agenda.

It is significant then that the public face of the movement for medicinal cannabis law reform has in significant part been children with paediatric epilepsy, a suite of conditions that are rare and heart-rending but not representative of the multifarious conditions for which it is claimed that medicinal cannabis has therapeutic efficacy. The plight of children such as Billy and Alfie in England, Suli in Queensland, Luella in New South Wales, and Cooper and Tara in Victoria is extremely distressing. Anecdotal assertions about the improvements experienced by them have played a key role in creating an environment that is receptive to reform to the unlawfulness of the use and possession of cannabis not just for paediatric epilepsy, but for a wide range of other medical conditions, including chronic pain. In fact, the day of establishing by sound medico-legal evidence the conditions for which medicinal cannabis, and the particular forms and dosages of medicinal cannabis, are efficacious for some patients are as yet some distance away and in respect of some conditions the emerging evidence is not propitious. Long-term effects of medicinal cannabis also remain unknown (see Aran and Cayam-Rand 2020). More importantly, even assuming the therapeutic efficacy of medicinal cannabis for paediatric epilepsy, it is does not follow that medicinal cannabis is efficacious or without adverse consequences for a wide variety of other conditions, still less that it is a desirable pharmacotherapy for conditions such as those involving chronic pain: the condition that has the potential to be the most lucrative for the cannabis industry if use and possession are decriminalised. Moreover, such evidence, properly evaluated, has little relevance to the arguments for and against the legalisation of recreational cannabis.

The use of emotive anecdotes and images of children, whose parents, not they, consent to high profile publicity, during their children's lives and even after their deaths, in support of cannabis legalisation campaigns is troubling. Before and after testimonials about 'cannabis children', especially when accompanied by photographs of children in the arms of their parents, can prompt visceral responses, but also leave a long term graphic digital footprint for the children. The issue of publicity raises questions about the responsibilities of parents in relation to creating a public profile for their ill children, based upon health information which would normally be private. It also raises confronting questions about the responsibilities of the media and of politicians (and even some entrepreneurial "cannabis doctors") who choose to publicise such "stories", whether that be for ratings, commercial advantage or as buttressing for what are perceived to be electorally appealing law reform initiatives.

The issue is not new, although on this occasion it has a distinctive aspect (Richards 2018). In the 1980s Jonsen (1986; see too McKie and Richardson 2003) coined the term, "rule of rescue" to argue that our "moral response to the imminence of death demands that we rescue the doomed, with the result that the deontological 
imperative prevails over issues in relation to costs." Big Cannabis/Big Weed, lobbyists and politicians are well aware of such perceived moral imperatives, as well as the optics, when named, seriously ill individuals (who are likely to be viewed sympathetically) are presented to the public, in respect of whom the adoption of a specific reformist step may make a therapeutic difference. In the context of making a breast cancer drug, Herceptin, available for patients under the Pharmaceutical Benefits Scheme, an analysis of 239 news items generated during a successful campaign to induce government to make the drug accessible led commentators to observe that although factors such as political pressure, patient advocacy and media hyperbole in principle should not play a role in determining who is treated and what they are treated with, the rule of rescue can be harnessed to exercise an important impact upon government decision-making (MacKenzie et al. 2008). The pressures in respect of the legalisation of medicinal cannabis, through the voices and images of children such as Billie, Alfie, Suli, Luella, Cooper and Tara, can be viewed in a similar way.

As became apparent from the Kiszko, King, Gard and Haarstrup cases, sick children in the media can elicit high levels of public sympathy. They can be potent instruments for argument, criticism of the status quo and the impetus for clinical and legal reforms. However, it is timely to reflect on where the limits should lie for such emotive use of the 'voices' and images of ill children - especially where there is the risk that their dignity and privacy are being unreasonably intruded upon and where other interests and agendas may be playing an undisclosed role that may not be compatible with the best interests of the children. This article is a first step in encouraging such reflective discussion in the context of the movement to decriminalise and evangelise the use of medicinal cannabis.

\section{Declarations}

Conflict of interest The author was the Commissioner at the Victorian Law Reform Commission who ran its reference on medicinal cannabis and is a member of the Australian Advisory Panel on Medicinal Cannabis. His views do not necessarily represent those of either institution.

\section{References}

Aguirre-Velazquez, C.G. 2017. Report from a survey of parents regarding the use of cannabidiol (medicinal cannabis) in Mexican children with refractory epilepsy. Neurology Research International. Accessed October 20 2021. 2021https://doi.org/10.1155/2017/2985729.

Andaloro, S. 2020. Parents hail 10-month-old's response to cannabis oil treatment as "amazing". 7 News. Accessed October 20, 2021, https://7news.com.au/lifestyle/health-wellbeing/parentshail-10-month-olds-response-to-cannabis-oil-treatment-as-amazing-c-1254326.

Aran, A., and Cayam-Rand. 2020. Medical cannabis in children. Ramban Mainomides Medical Journal 11 (1): e0003. https://doi.org/10.5041/RMMJ.10386.

Arnold, J.C., T. Nation, and I.S. McGregor. 2020. Prescribing medicinal cannabis. Australian Prescriber 43: 152-159.

Asadi-Pooya, A.A. 2017. Lennox-Gastaut syndrome: A comprehensive review. Neurological Sciences 39: 403-418. 
Asterion 2021 Merger announced with ANTG and Asterion - developing one of the world's biggest medicinal cannabis facilities. Accessed October 20, 2021, https://www.asterioncannabis.com/_ resources/news/nr_2021-04-12.pdf.

Auckland, C., and I. Goold. 2019. Parental rights, best interests and significant harms: Who should have the final say over a child's medical care? The Cambridge Law Journal 78 (2): 287-323.

Australian Medical Association. (2020). AMA submission to Senate Inquiry into the barriers to patient access to medicinal cannabis in Australia.

Australian and New Zealand College of Anaesthetists, Faculty of Pain Medicine 2021. Accessed October 20, 2021, https://www.anzca.edu.au/news/top-news/fpm-and-medicinal-cannabis.

Backes, M. 2014. Cannabis pharmacy. Black Fog and Doubleday.

Barratt, A. 2014. Zoe's Law could take NSW backwards in women's rights. The Conversation. Accessed October 20, 2021, https://theconversation.com/zoes-law-could-take-nsw-backw ards-in-womens-rights-33681.

Birchley, B., R. Gooberman-Hill, Z. Deans, et al. 2017. 'Best interests' in paediatric intensive care: An empirical ethics study. Archives of Disease in Childhood 102 (10): 930-935. https://doi.org/ 10.1136/archdischild-2016-312076.

Booth, M. 2003. Cannabis: A history. (Doubleday).

Brick, C., G. Kahane, D. Wilkinson, L. Caviola, and J. Saulescu. 2020. Worth living or worth dying? The views of the general public about allowing disabled children to die. Journal of Medical Ethics 46 (1): 7-15.

Bridgeman, M.B. 2017. Medicinal cannabis: History, pharmacology and implications for the acute care setting. Pharmacy and Therapeutics 42 (3): 180-188.

Busby, M. 2018a. Mother of epileptic boy will not get confiscated cannabis oil back. The Guardian. Accessed October 20, 2021, https://www.theguardian.com/society/2018/jun/11/epileptic-boysmother-barred-from-bringing-cannabis-oil-into-uk.

Busby, M. 2018b. MPs condemn UK cannabis laws after epileptic boy's medication seized. The Guardian. Accessed October 20, 2021, https://www.theguardian.com/society/2018/jun/12/mps-condemnuk-cannabis-laws-after-epileptic-boy-billy-caldwell-medication-seized.

Busby, M. 2018c. Billy Caldwell licensed for cannabis oil use in Northern Ireland. The Guardian. Accessed October 20, 2021, https://www.theguardian.com/society/2018/jul/05/billy-caldwellheads-home-amid-doubts-over-cannabis-oil-access-northern-irleand-medication-epilepsy.

Busby, M. 2018d. Mother says cannabis oil has been savior for epileptic son Alfie. The Guardian. Accessed October 20, 2021, https://www.theguardian.com/society/2018/nov/01/mother-says-canna bis-oil-has-been-saviour-for-epileptic-son-alfie.

Butcher, K. 2020. Baby girl spared from induced coma thanks to cannabis treatment for seizures. Babygaga. Accessed October 20, 2021, https://www.babygaga.com/baby-girl-cannabis-oil-seizures/.

Canna Reviews Australia. 2021 Australian cannabis clinic prices. Accessed October 20, 2021, https:// cannareviewsau.co/cannabis-clinic-price-comparison.

Cannabis Club Australia. 2020. Parents Hail 10-month-old's response to cannabis oil treatment as amazing. Cannabis Club Australia. Accessed October 20, 2021, https://www.cannabisclubaustralia. com.au/single-post/2020/08/21/parents-hail-10-month-olds-response-to-cannabis-oil-treatment-asamazing.

Cannabis Doctors Australia - ACT. 2021. Australia's Leaders in Medicinal Cannabis. Accessed October 20, 2021, https://healthengine.com.au/medicinal-cannabis-clinic/act/canberra/cannabis-doctorsaustralia-australian-capital-territory/s75512.

Catarino, C.B., J.Y.W. Liu, I. Liagkouras, et al. 2011. Dravet syndrome as epileptic encephalopathy: Evidence from long-term course and neuropathology. Brain 134 (10): 2982-3010.

Chen, J.W., L.M. Borgelt, and A.B. Backmer. 2019. Cannabidiol: A new hope for patients with Dravet or Lennox-Gastaut syndromes. Annals of Pharmacotherapy 53 (6): 603-611. https://doi.org/10.1177/ 1060028018822124.

Clarke, R., Merlin, M. 2016. Cannabis: Evolution and ethnobotany. University of California Press.

Connor, F. 2018. Australia's first medicinal cannabis clinic set to open in Melbourne - As it's revealed an additional nine will be launched next year. Daily Mail Australia. Accessed October 20, 2021, https://www.dailymail.co.uk/news/article-5876593/Australias-medicinal-cannabis-clinic-set-open. $\mathrm{html}$.

Cook, H. 2014. Labor pledge to legalise medical marijuana if it wins Victorian election. The Age. Accessed October 20, 2021, https://www.theage.com.au/national/victoria/labor-pledge-to-legalisemedical-marijuana-if-it-wins-victorian-election-20140824-107vg4.html. 
Cvitanovic-Sojat, L., R. Gjergja, Z. Sabol, et al. 2005. Treatment of west syndrome. Acata Medica Croatica 59 (10): 19-29.

Daly, J. 2021. Australia's biggest medicinal marijuana farm to be built in Queensland's conservative garden city. ABC News. Accessed October 20, 2021, https://www.abc.net.au/news/rural/2021-04-15/ australias-biggest-medicinal-cannabis-farm-toowoomba/100070770.

Deacon, H. 2019. Why I campaign for children like my son Alfie Dingley to be able to get medicinal cannabis. British Medical Journal 365: 1921.

Desloires, V., Battersbly, L. 2014. Victoria to legalise medicinal marijuana. The Age. Accessed October 20, 2021, https:/www.theage.com.au/national/victoria/victoria-to-legalise-medicinal-marijuana20141219-12ary3.html.

Devinsky, O., J.H. Cross, L. Laux, et al. 2017. Trial of cannabidiol for drug-resistant seizures in the Dravet syndrome. New England Journal of Medicine 376: 2011-2020.

Devinsky, O., A.D. Patel, J.H. Cross, et al. 2018. Effect of cannabidiol on drop seizures in the LennoxGastaut syndrome. New England Journal of Medicine 378: 188801897.

Dravet Foundation, What is Dravet Syndrome? Accessed October 20, 2021, https://www.dravetfoun dation.org/what-is-dravet-syndrome/.

Fischer, B., and W. Hall. 2021. New Zealand's failed cannais legalization referendum - Ramifications for cannabis policy reform. The Lancet Regional Health - Western Pacific. https://doi.org/10.1016/j. lanwpc.2020.100080.

Freckelton, I. 2016a. Parents' opposition to potentially life-saving treatment for minors: Learning from the Oshin Kiszko Litigation. Journal of Law and Medicine 24 (1): 61-71.

Freckelton, I. 2016b. Futility of treatment for dying children. Lessons from the Charlie Gard case. Journal of Law and Medicine 25: 7-29.

Freckelton, I. 2018. Responding better to desperate parents: Warnings from the Alfie Evans saga. Journal of Law and Medicine 25: 899-918.

Frew, C. 2021. Mother urges government to allow wider prescriptions of cannabis for her 0-year old son. UNILAD. Accessed October 20, 2021, https://www.unilad.co.uk/news/mother-urges-governmentto-allow-wider-prescriptions-of-cannabis-for-her-9-year-old-son/.

Gale, S.F. 2020. Sparking the cannabis industry. Insigniam quarterly. Accessed October 20, 2021, https:// quarterly.insigniam.com/innovation/sparking-the-cannabis-industry/.

Gleeson, P. 2020. The challenge of medicinal cannabis to the political legitimacy of therapeutic goods regulation in Australia. Melbourne University Law Review 43 (2): 558-604.

Gregoire, P. 2020. Suli deserves a full inquest: An interview with medicinal cannabis advocate Steve Peek. Sydney Criminal Lawyers. Accessed October 20, 2021, https://www.sydneycriminall awyers.com.au/blog/suli-deserves-a-full-inquest-an-interview-with-medicinal-cannabis-advoc ate-steve-peek/.

Grierson, J., Busby, M. 2018. Home secretary announces review into medicinal cannabis use. The Guardian. Accessed October 20, 2021, https://www.theguardian.com/society/2018/jun/19/home-secre tary-sajid-javid-announces-review-into-medicinal-cannabis-use.

Hageseth, C., and D’Agnese, J. 2015. Big weed. (St Martin's Press).

Halperin, A. 2018. Cannabis capitalism: Who is making money in the marijuana industry? The Guardian. Accessed October 20, 2021, https:/www.theguardian.com/society/2018/oct/03/cannabis-industrylegalization-who-is-making-money.

Hauser W., Petzke F., and Fitzcgarles M.A. 2018. Efficacy, tolerability and safety of cannabis-based medicines for chronic pain management - An overview of systematic reviews. European Journal of Pain 22 (3): 455-470. https://doi.org/10.1002/ejp.1118

Hunt, G. 2018. Australian government to allow medicinal cannabis experts. Accessed October 20, 2021, https://www.health.gov.au/ministers/the-hon-greg-hunt-mp/media/australian-government-to-allowmedicinal-cannabis-exports.

Hunt, G. 2021. Historic listing for Australians with an epilepsy condition. Accessed October 20, 2021, https://www.health.gov.au/ministers/the-hon-greg-hunt-mp/media/historic-pbs-listing-for-austr alians-with-a-rare-epilepsy-condition.

International Association for the Study of Pain. 2021. IASP position statement on the use of cannabis to treat Pai. Accessed October 20, 2021, https://www.iasp-pain.org/PublicationsNews/NewsDetail. aspx ? ItemNumber $=11145 \&$ navItemNumber $=643$.

Isaacs, D., and A. Preisz. 2019. Splitting. Journal of Paediatrics and Child Health 55 (10): 1159-1160. 
Johns, D. and Spooner, R. 2014. Police question pregnant mother on treatment for disabled son. The Age. Accessed October 20, 2021, https:/www.theage.com.au/national/victoria/police-question-pregn ant-mother-over-cannabis-treatment-for-disabled-son-20140710-zt35v.html.

Jonas, M., and S. Ryan. 2020. The discourse of dignity in the Charlie Gard, Alfie Evans and Isaiah Haarstrup Cases. Medical Law Review. https://doi.org/10.1111/bioe.12749.

Jonsen, A.R. 1986. Bentham in a box: Technology assessment and health care allocation. Law Medicine and Health Care 14: 172-174.

Karila, L., P. Roux, B. Rolland, et al. 2014. Acute and long-term effects of cannabis use: A review. Current Pharmaceutical Design 20 (25): 4112-4118. https://doi.org/10.2174/13816128113199990620.

Keyte, M. 2017. Parents' choice: Break the law or bury your child. Seniors. Accessed October 20, 2021, https://www.seniorsnews.com.au/news/parents-choice-break-the-law-or-bury-your-child/3131620/.

Kolmar, C. 2021. 15 Largest cannabis companies in the world. Zippia. Accessed October 20, 2021, https://www.zippia.com/advice/largest-cannabis-companies/.

Lagae, L., H. Verhelst, and B. Ceulemans. 2010. Treatment andlong term outcome in west syndrome: The clionical reality. A multicentre follow up study. Zisure 19 (3): 159-164. https://doi.org/10.1016/j. seizure.2010.01.008.

Lancaster, K., K. Seear, and A. Ritter. 2017. Making medicine; producing pleasure: A critical examination of medicinal cannabis policy and law in Victoria, Australia. International Journal on Drug Policy 49: 117-125.

Laszewska-Hellriegel, M. 2019. The cases of Alfie Evans and Charlie Gard. Who should decide when to end a therapy? Ethique and Sante 16 (2): 71-80.

MacKenzie, R., S. Chapman, G. Salkeld, and S. Holding. 2008. Media influence on Herceptin subsidization in Australia: Application of the rule of rescue? Journal of the Rouyal Society of Medicine 101 (6): 305-312.

McDougall, R. 2016. When parents disagree with doctors on a child's treatment, who should have the final say? The Conversation. Accessed October 20, 2021, https://theconversation.com/when-paren ts-disagree-with-doctors-on-a-childs-treatment-who-should-have-the-final-say-64813.

McKie, J., and J. Richardson. 2003. The rule of rescue. Social Science and Medicine 56: 2407-2413.

Medical Cannabis Users Association of Australia, 2021. (2021). About Us. Accessed October 20, 2021, https://www.mcuainc.org.au/about.html.

Mellor, L. 2018a. Brisbane father blames barriers to cannabis oil for daughter's death. ABC News. Accessed October 20, 2021, https://www.abc.net.au/news/2018-03-11/father-blames-barriers-tocannabis-oil-for-daughters-death/9510486.

Mellor, L. 2018b. Claim doctors 'turn a blind eye' to medical cannabis in hospital. The New Daily. Accessed October 20, 2021, https://thenewdaily.com.au/news/national/2018/03/15/doctors-alleg edly-turn-a-blind-eye-to-cannabis-being-given-to-children-in-hospital/.

Miller, I., I.E. Scheffer, B. Gunning, et al. 2020. Dose-ranging effect of adjunctive oral cannabidiol vs placebo on convulsive seizure frequency in Dravet syndrome: A randomised clinical trial. JAMA Neurology 77: 613-621.

Montgomery, J. 2019. The 'tragedy' of Charlie Gard: A case study for regulation. Law Innovation and Technology 11 (1): 155-174.

Moore, M., and J.D. Lantos. 2019. When parents take conflicts to digital media. Pediatrics 144 (2): e20190932.

Nadler, J. 2019. Mother of Alfie Dingley joins Lyphe Group to improve access to medical cannabis. Accessed October 20, 2021, https://lyphegroup.com/alfie-dingley/.

National Academies of Sciences, Engineering, and Medicine 2017. The health effects of cannabis and cannabinoids: The current state of evidence and recommendations for research. Washington (DC): National Academies Press

National Institute for Health and Care Excellence 2019. Cannabidiol with clobazam for treating seizures associated with Lennox-Gastaut syndrome. Accessed October 20, 2021, https://www.nice.org.uk/ guidance/TA615/chapter/1-Recommendations.

Nelson N. 2020. Mum of epilsptic boy urges Boris Johnson to allow doctors to prescribe canabis. The Mirror. Accessed October 20, 2021, https://www.mirror.co.uk/news/uk-news/mum-epileptic-boyurges-boris-24355932

Nugent, S.M., B.J. Morasco, and M.E. O'Neil. 2017. The effects of cannabis among adults with chronic pain and an overview of general harms: A systematic review. Annals of Internal Medicine 167 (5): 319-331. https://doi.org/10.7326/M17-0155. 
O'Brien, A., and D.K. Sokol. 2014. Lessons from the Ashya King case. British Medical Journal 349: g5563.

O'Carroll, L. 2021. Mother fears son could die as Brexist stops medical cannabis supply. The Guardian. Accessed October 20, 2021, https://www.theguardian.com/politics/2021/jan/05/mother-fears-soncould-die-as-brexit-stops-medical-cannabis-medicine-supply.

Okninski, M. 2016. Determining a Child's best interests when parents refuse medical treatment - CAHS v Kiszko and Anor [2016] FCWA. Journal of Bioethical Inquiry 13 (3): 364-368.

Peek. S. Steven peek. United in Compassion. Accessed October 20, 2021, https://unitedincompassion. com.au/steve-peek/.

Pratt, M., A. Stevens, M. Thuku, et al. 2019. Benefits and harms of medical cannabis: A scoping review of systematic reviews. Systematic Reviews 8: 320.

Reiff, N 202110 biggest Canadian marijuana companies. Investopedia. Accessed October 20, 2021, https://www.investopedia.com/top-canadian-cannabis-companies-by-revenue-4587803.

Reis, R., K.J. AlmeidaLopes, et al. 2019. Efficacy and adverse event profile of cannabidiol and medicinal cannabis fpr treatment-resistant epilepsy: A systematic review and meta-analyis. Epilepsy and Behavior 102: 106635. https://doi.org/10.1016/j.yebeh.2019.106635.

Resnick, T., and R.D. Sheth. 2017. Early diagnosis and treatment of Lennox-Gastaut syndrome. Journal of Child Neurology 32 (11): 947-955.

Richards, B.J. 2018. Social media: The unnamed plaintiff. Journal of Bioethical Inquiry 15 (3): 309-312.

Roberts, C. 2021. Bid weed is here: Marijuana legalization spreads, budding big business green. The Observer. Accessed October 20, 2021, https://observer.com/2021/02/big-weed-is-here-marijuanalegalization-spreads-budding-big-business-green/.

Rose, D. 2015. Vic to lead nation on medicinal cannabis. The Weekly Times. Accessed October 20, 2021, https://www.weeklytimesnow.com.au/news/national/vic-to-get-medicinal-cannabis-advice/newsstory/1ceac48b1ceac2410b162d9a5bfe0e57.

Ross, L.F. 2020. Reflections on the Charlie Gard and the best interests standard from both sides of the Atlantic Ocean. Pediatrics 146 (Supp 1): S60-S65.

Russo, E.B. 2003. Cannabis: From pariah to prescription. Taylor and Francis.

Rychert, M., and C. Wilkins. 2021. Why did New Zealand's referendum to Legalise recreational cannabis fail? Drug and Alcohol Review. https://doi.org/10.1111/dar.13254.

Savulescu, J. and Wilkinson, D 2018 Ethics, conflict and medical treatment for children: From disagreement to dissensus. Elsevier.

Smith, G.L. 2016. Medical cannabis: Basic science and clinical applications. Aylesbury Press.

Specchio, N., M. Trivisano, F. Vigevano, et al. 2010. Idiopathic west syndrome followed by childhood absence epilepsy. Seizure. 19 (9): 597-601. https://doi.org/10.1016/j.seizure.2010.07.016.

Summers, D.J. 2018. The business of cannabis. Praeger.

Therapeutic Goods Administration. 2017. Guidance for the use of medicinal cannabis in Australia: Patient administration. Accessed October 20, 2021, https://www.tga.gov.au/publication/guidanceuse-medicinal-cannabis-australia-patient-information.

Therapeutic Goods Administration. 2019. Medicinal cannabis: Importation and the Traveller's exemption. Accessed October 20, 2021, https://www.tga.gov.au/medicinal-cannabis-importation-andtravellers-exemption.

Therapeutic Goods Administration. 2020. Medicinal cannabis - Guidance documents. Accessed October 20, 2021, https://www.tga.gov.au/medicinal-cannabis-guidance-documents\#guidance-docs.

Therapeutic Goods Administration. 2021a. Special access scheme. Accessed October 20, 2021, https:// www.tga.gov.au/form/special-access-scheme.

Therapeutic Goods Administration. 2021b. Authorised prescribers. Accessed October 20, 2021, https:// www.tga.gov.au/form/authorised-prescribers.

Thiele, E.A., E.D. Marsh, and J.A. French. 2018. Cannabidiol in patients with seizures associated with Lennox-Gastaut syndrome (GWPCARE4): A randomised, double-blind, placebo-controlled phase-3 trial. Lancet 391: 1085-1096.

Thomsen, S. 2015. Victoria is legalising medical cannabis in 2017. Business Insider Australia. Accessed October 20, 2021, https://www.businessinsider.com.au/victoria-is-legalising-medical-canna bis-in-2017-2015-10.

Tozer, J. 2015. Medical marijuana credited with flgirl's 'miracle/recovery. SBS News. Accessed October 20, 2021, https://www.sbs.com.au/news/medical-marijuana-credited-with-girl-s-miracle-recovery. 
Vagg, M. 2021. Medicinal cannabis to manage chronic pain? We don't have the evidence it works. The Conversation. Accessed October 20, 2021, https://theconversation.com/medicinal-cannabis-tomanage-chronic-pain-we-dont-have-evidence-it-works-157324.

Victorian Law Reform Commission. 2015. Medicinal Cannabis. VLRC. Accessed October 20, 2021, https://www.lawreform.vic.gov.au/sites/default/files/VLRC_Medicinal_Cannabis_Report_web.pdf.

Victorian State Government, Justice and Community Safety, 'What is Brodie's Law? 2011. Accessed October 20, 2021, https://www.justice.vic.gov.au/safer-communities/crime-prevention/bullyingbrodies-law.

Villas, N., M.A. Meskis, and S. Goodliffe. 2017. Dravet syndrome: Characteristics, comorbidities and caregiver concerns. Epilepsy and Behavior 74: 81-86.

Von Wred, R., C. Helmstaedter, and R. Surges. 2021. Cannabidiol in the treatment of epilepsy. Clinical Drug Investigation 41: 211-220.

Von Wrede, R., C. Helmstaedtler, and R. Surges. 2021. Cannabidiol in the treatment of epilepsy. Clinical Drug Investigation 41 (3): 211-220.

Wedman-St Louis, B. 2019. Cannabis as medicine. CRCX Press.

Wheeler, R. 2018. Observations on the case of Charlie Gard. Archives of Disease in Childhood 103: 410-411.

Wilkie, K. 2021. Parents of baby girl suffering with horrendous seizures so painful doctors wanted to put her in a coma say CANNABIS is saving her life. Daily Mail Australia. Accessed October 20, 2021, https://www.dailymail.co.uk/news/article-8648987/Parents-baby-girl-suffering-horrendous-seizu res-say-CANNABIS-oil-saving-life.html.

Wilkins, C., J.L. Reilly, M. Pledger, and S. Casswell. 2005. Estimating the dollar value of the illicit market fort cannabis in New Zealand. Drug and Alcohol Review 24 (3): 227-234.

Younger, D.S. 2018. The science of medical cannabis. Nova Science Publishers.

Zahra, E. Darke, S. Degenhardt, L. et al. 2020. Rates, characteristics and manner of cannabis-related deaths in Australia 2000-2018. Drug and Alcohol Dependence. 212: 108028. Accessed October 20, 2021, https://www.sciencedirect.com/science/article/abs/pii/S0376871620301939?via\% 3Dihub.

Publisher's Note Springer Nature remains neutral with regard to jurisdictional claims in published maps and institutional affiliations. 